\title{
Impact of COVID-19 on the Noncommunicable Disease Programs Provided in the Primary Health Care Centers in Al-Rusafa Directorate of Health, 2020
}

Mohammed Hlaiwah ${ }^{1}$, MBChB, FETP High Diploma; Faris Lami ${ }^{2}$, MBChB, PhD, FFPH

${ }^{1}$ Ministry of Health, Baghdad, Iraq

${ }^{2}$ Ministry of Higher Education, Baghdad, Iraq

Corresponding Author:

Faris Lami, MBChB, PhD, FFPH

Ministry of Higher Education

Jadiriya

Baghdad

Iraq

Phone: 9647901402692

Email: farislami@gmail.com

\section{Abstract}

Background: In recent years, noncommunicable diseases (NCDs) have globally shown an increasing impact on health status with disproportionately higher rates in developing countries. During the outbreak, health workers, equipment, and facilities have been reallocated to address the influx of patients with COVID-19. Restructuring of the health system could result in the closure of some health facilities.

Objective: The aim of this paper was to determine the impact of COVID-19 on the performance of NCD programs implemented in the primary health care centers in Al-Rusafa DOH through comparing the performance indicators of 2019 and 2020 , and to identify the potential causes of the changes.

Methods: The study was conducted in Baghdad, Al-Rusafa, during the period from April to June 2021. A systematic sample was used to enroll 20 primary health care centers. The descriptive analysis focused on frequencies and percentages. Continuous variables are presented as mean (SD), and the independent $t$ test was used to assess statistical significance. A $P$ value of less than .05 is considered statistically significant.

Results: There was a decrease in the number of served patients, even reaching zero in some units. Most staff were partially or completely assigned to the COVID-19 pandemic. There was a decline in yearly need of education material and folders for programs in 2020 and awareness campaigns performed in 2019 and 2020. The main reasons in the decline of these services were the closure of outpatient services as per government directive, the closure of outpatient disease-specific consultation clinics, and the decrease in outpatient volume due to patients not presenting.

Conclusions: The COVID-19 pandemic affected the NCD services in Iraq, including the disruption of many aspects of these services.

(iproc 2022;8(1):e36449) doi: $10.2196 / 36449$

\section{KEYWORDS}

Iraq; noncommunicable diseases; NCDs; primary health care centers; PHCCs; COVID-19 
Edited by Y Khader; this is a non-peer-reviewed article. Submitted 15.01.22; accepted 27.01.22; published 10.02.22.

Please cite as:

Hlaiwah $M$, Lami F

Impact of COVID-19 on the Noncommunicable Disease Programs Provided in the Primary Health Care Centers in Al-Rusafa

Directorate of Health, 2020

iproc 2022;8(1):e36449

URL: https://www.iproc.org/2022/1/e36449

doi: $10.2196 / 36449$

PMID:

CMohammed Hlaiwah, Faris Lami. Originally published in Iproceedings (https://www.iproc.org), 10.02.2022. This is an open-access article distributed under the terms of the Creative Commons Attribution License (https://creativecommons.org/licenses/by/4.0/), which permits unrestricted use, distribution, and reproduction in any medium, provided the original work, first published in Iproceedings, is properly cited. The complete bibliographic information, a link to the original publication on https://www.iproc.org/, as well as this copyright and license information must be included. 